$\begin{array}{ll}\text { Volume } & : 7 \\ \text { Nomor } & : \mathbf{3} \\ \text { Bulan } & : \text { Agustus } \\ \text { Tahun } & : \mathbf{2 0 2 1}\end{array}$

\title{
Sirkumstansialisasi sebagai Piranti Representasi Inklusif Aktor Sosial dalam Pidato Politik (Sebuah Tinjauan Analisis Wacana Kritis Pidato Politik Hasan Rouhani)
}

\author{
Rahmatan Idul \\ Fakultas Sastra dan Budaya Universitas Negeri Gorontalo \\ Pos-el: Rahmatan_idul@ung.a.c.id
}

DOI: 10.32884 /ideas.v7i3.387

\begin{abstract}
Abstrak
Penelitian ini bertujuan untuk menyelidiki penggunaan sirkumstansialisasi dalam merepresentasikan secara inklusif aktor-aktor sosial yang terlibat dalam pidato politik Hassan Rouhani yang disampaikan di depan Sidang Umum Perserikatan Bangsa-Bangsa. Data diperoleh dari salah satu laman berita resmi Israel (www.timesofisrael.com) berupa 116 kalimat hasil transkripsi pidaro tersebut yang kemudian dianalisis menggunakan kerangka analisis aktor sosial Theo van Leeuwen. Kalimat-kalimat ini kemudian dielaborasi melalui teknik parafrase, yakni memodifikasinya secara struktural dengan tetap mempertahankan maknanya untuk mengungkap representasi inklusif aktor-aktor sosialnya. Hasilnya kemudian disajikan secara deskriptif. Pilihan linguistik Hassan Rouhani menekankan penggunaan preposisi sirkumstansial untuk melibatkan aktoraktor sosial tertentu dalam pidato politiknya secara inklusif. Terdapat sembilan jenis preposisi yang digunakan Hassan Rouhani dalam pidatonya, yakni "against", "among", dan "for" untuk merepresentasikan peran pasif aktor-aktor sosial, preposisi "by", "from", dan "under" untuk menggambarkan peran aktif aktor-aktor sosial, preposisi "between" untuk menggambarkan peran yang berbeda dari aktor-aktor sosial (aktif dan pasif), preposisi "with" untuk menampilkan peran netral aktor-aktor sosial, dan preposisi "of" untuk memisahkan aktor-aktor social yang berperan aktif sebagai pelaku dan aktor-aktor social yang berperan pasif sebagai korban.
\end{abstract}

\section{Kata Kunci}

analisis wacana kritis, sirkumstansialisasi, aktor sosial, pidato politik

\begin{abstract}
Exerting van Leeuwen's framework, this study aims at critically investigating the employment of circumstantialization in inclusively representing social actors involved in Hassan Rouhani's political speech delivered in front of the General Assembly of the United Nations. Data were derived from one of Israel's official websites (www.timesofisrael.com). Out of 116 sentences in the transcription of the speech, the relevant ones were selected to be analyzed using Theo van Leeuwen's framework 'Social Actor Analysis.' These sentences were then elaborated through a paraphrase technique by structurally modifying them while maintaining their meaning to reveal social actors' inclusive representation. The results were then presented descriptively. Hasan Rouhani's linguistic choices accentuate the use of circumstantial prepositions to involve certain social actors in his political speech inclusively. Nine types of prepositions were employed in his speech. Hasan Rouhani used the preposition "against," "among," and "for" to represent the social actors in passive roles, the preposition "by," "from," and "under" to delineate the social actors in active roles, the preposition "between" to illustrate different roles of the social actors (active and passive) in social action, the preposition "with" to display the neutral role of the social actors, and the preposition "of" to indicate the active role or the passive role of the social actors.
\end{abstract}

Keywords

critical discourse analysis, circumstantialization, social actor, political speech

\section{Pendahuluan}

Wacana, sebagaimana dikemukakan oleh Fairclough \& Norman (2013), merupakan salah satu bentuk praktik sosial yang mengacu pada setiap jenis komunikasi lisan dan tertulis. Dalam hal ini komunikasi yang dimaksud dalam konteks ini adalah interaksi yang terjadi secara alamiah melalui media bahasa (Johnstone, 2008). Selain itu, van Leeuwen (2008) menegaskan bahwa sebagai kognisi sosial, wacana dapat digunakan sebagai sumber untuk merepresentasikan praktik-praktik sosial dalam teks. Dalam pengertian ini, praktik sosial terdapat pada

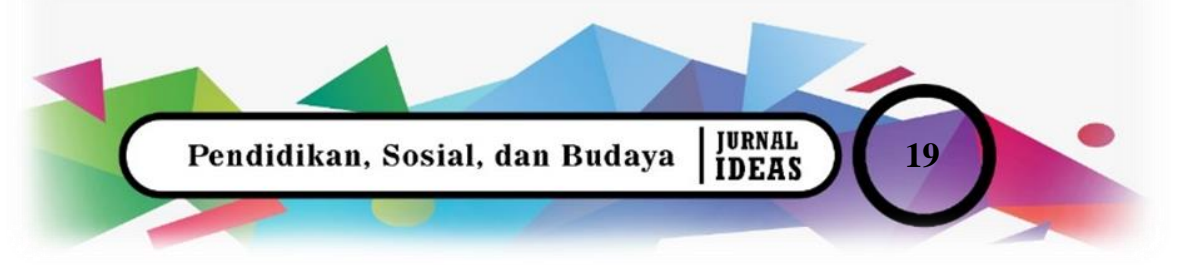




\begin{tabular}{c|ll} 
E-ISSH: 2656-940X & Volume & $: 7$ \\
Nomor & $: 3$ \\
P-ISSH: 2442-367K & Bulan & $:$ Agustus \\
Tahun & $: 2021$
\end{tabular}

setiap bentuk komunikasi, seperti surat pribadi, laporan surat kabar, pembicaraan keluarga, atau pidato politik. Praktik sosial mencakup beberapa unsur, yaitu aktor sosial, tindakan atau aksi sosial, mode kinerja, syarat kelayakan (partisipan), gaya presentasi, waktu, lokasi, syarat kelayakan (lokasi), sumber daya (alat dan bahan), dan syarat kelayakan (sumber daya) (van Leeuwen, 2008).

Dari semua jenis komunikasi, seperti yang telah disebutkan sebelumnya, pidato politik adalah yang paling banyak memuat praktik sosial. Pidato politik, sebagaimana pendapat Finlayson \& Martin (2008), secara umum digambarkan sebagai upaya memberikan alasan kepada orang lain untuk berpikir, merasa, atau bertindak dengan cara tertentu, untuk membujuk mereka agar memberikan kepercayaan kepada seseorang dalam situasi yang tidak menentu, atau untuk membuat mereka melihat sesuatu dari sudut pandang tertentu. Dengan kata lain, pidato politik umumnya digunakan untuk meyakinkan khalayak untuk mendukung perspektif pembicara tentang suatu fenomena atau untuk menyamarkan, mengubah, atau menyembunyikan fenomena tertentu.

Salah satu pidato politik yang merepresentasikan praktik sosial yang juga menjadi objek material kajian ini adalah pidato yang disampaikan oleh Hasan Rouhani (selanjutnya disebut HR) pada Sidang Umum PBB pada tanggal 24 September 2013. Sebagai presiden baru Iran menggantikan Ahmadinejad, pidato ini perlu dikaji guna mengidentifikasi bagaimana HR memposisikan Iran dan dirinya sebagai pemimpin tertinggi Iran terkait krisis yang tengah melanda Timur Tengah saat itu dan mengetahui reaksi Iran terhadap penolakan Israel dan sekutunya terhadap program pengembangan nuklir mereka.

Di antara semua elemen praktik sosial, yang paling menonjol dalam pidato HR adalah aktor sosial. Aktor sosial, sebagai salah satu elemen penting dari praktik sosial, direpresentasikan oleh van Leeuwen (2008) melalui dua cara, yaitu eksklusi dan inklusi. Dalam eksklusi, van Leeuwen menggunakan strategi pasivasi untuk menyembunyikan pelaku, nominalisasi untuk menggeser fokus dari pelaku ke peristiwa, dan klausa infinitif. Sedangkan dalam inklusi, van Leeuwen menggunakan strategi determinasi, indeterminasi, abstraksi, objektivasi, diferensiasi, kategorisasi, fungsionalisasi, identifikasi, asimilasi, individualisasi, dan sirkumtansialisasi untuk membuat aktor-aktor sosial yang terlibat dalam wacana menjadi inklusif. Salah satu piranti representasi inklusif aktor sosial yang cukup banyak ditemui dalam pidato HR adalah strategi sirkumstansialisasi, yakni jenis inklusi yang merepresentasikan aktor sosial sebagai pihak yang aktif atau pasif dalam suatu aksi sosial melalui preposisi sirkumstansial seperti against, among, between, by, from, of, atau under.

Sejauh ini, sebagian besar studi terhadap representasi aktor sosial hanya berusaha mengungkapnya secara umum, baik secara inklusif maupun eksklusif. De Oliveira (2015) secara khusus mengkaji ketiadaan tema dan partisipan oleh kelompok yang terlibat revolusi secara langsung dalam pidato Presiden Portugis, Cavaco Silva, pada pembukaan resmi peringatan 40 tahun kudeta militer 25 April 1974. Hasil studi ini mengonfirmasi dibungkamnya suara-suara penting Revolusi pada peringatan resmi di tahun 2014. Penelitian lain oleh Esmaeili \& Arabmofrad (2015) menyelidiki representasi linguistik aktor sosial laki-laki dan perempuan dalam Family and Friends 4, 5, and 6. Keduanya menggunakan kerangka representasi van Leeuwen dan teori transitivitas Halliday dan Matthiessen untuk mengungkap ideologinya. Temuannya menunjukkan "sikap seksis" yang berpihak pada aktor sosial laki-laki dan upaya untuk menghindari stereotip tradisional perempuan. Studi terhadap representasi aktor sosial juga dilakukan oleh Bernard (2016) yang mengkaji representasi aktor sosial dalam dua jenis teks yang kontras, yaitu laporan Corporate Social Responsibility (CSR) Lonmin dan transkrip kesaksian yang diberikan di Komisi Penyelidik Marikana. Temuannya menyoroti dominasi ideologi neoliberal di industri pertambangan Afrika Selatan dan kemungkinan implikasi dari sektor ini bagi transformasi di masa depan. Selain itu, dalam kajiannya, El Kadri (2018) memfokuskan analisisnya pada identitas Pibdian dalam program pendidikan guru di Brasil, yang dibangun melalui 'diferensiasi', 'normalisasi', dan 'identitas afinitas'. Kajian lain yang menggunakan kerangka aktor sosial van Leeuwen dilakukan oleh Roohani dan Heidari (2012) yang berupaya mengevaluasi buku Summit 2B (seri lanjutan dari Top Notch) dengan berfokus pada representasi aktor sosial pria dan wanita. Temuannya menunjukkan bahwa meskipun representasi perempuan dan laki-laki hampir ekual, tidak ada upaya serius untuk menghilangkan bias gender dalam buku Summit $2 B$ yang digunakan sebagai pengganti buku teks ELT lain di lembaga-lembaga bahasa swasta di Iran.

Dari keseluruhan kajian terhadap representasi aktor sosial dalam sebuah wacana tersebut, belum ada satu pun kajian yang secara khusus membahas representasi inklusif aktor sosial melalui sirkumstansialisasi. Oleh karena itu, penelitian ini bertujuan untuk menyelidiki secara kritis penggunaan sirkumstansialisasi dalam 


$\begin{array}{ll}\text { Volume } & : 7 \\ \text { Nomor } & : \mathbf{3} \\ \text { Bulan } & : \text { Agustus } \\ \text { Tahun } & : 2021\end{array}$

merepresentasikan secara inklusif aktor sosial yang terlibat dalam pidato politik HR.

\section{Metode}

Data primer dalam penelitian ini berupa 116 kalimat hasil transkripsi pidato politik HR yang diperoleh dari salah satu situs resmi Israel (www.timesofisrael.com). Data tersebut dianalisis menggunakan pendekatan analisis aktor sosial van Leeuwen (2008), yang dielaborasi melalui teknik paraphrase, dimana kalimat-kalimat tersebut dimodifikasi secara struktural dengan tetap mempertahankan maknanya untuk mengungkap representasi inklusif aktor-aktor sosialnya. Hasil analisis kemudian disajikan secara deskriptif.

\section{Hasil dan Pembahasan}

Hasil

Sirkumstansialisasi adalah salah satu jenis inklusi yang merepresentasikan aktor sosial sebagai pihak yang aktif atau pasif dalam suatu aksi sosial di mana mereka terlibat. Adanya inklusi ini diindikasikan dengan adanya preposisi tidak langsung. HR menggunakan banyak preposisi tidak langsung dalam pidatonya. Penggunaan preposisi ini dimaksudkan untuk merepresentasikan aktor sosial yang terlibat dalam praktik sosial dalam pidato secara inklusif. Namun, setiap preposisi memiliki fungsi yang berbeda seperti yang ditunjukkan pada tabel berikut.

\section{Tabel 1}

Preposisi Sirkumstansial dalam Pidato HR

\begin{tabular}{lll}
\hline Preposisi & Data & Alokasi Peran \\
\hline Against & S.28, S.37, S.38, S.104 & Pasif \\
Among & S.21 & Aktif-Pasif \\
Between & S.25 & Aktif-Pasif \\
By & S.7, S.8, S.24, S.45, S.85, S.98 & Aktif \\
From & S.101 & Aktif \\
Under & S.39 & Aktif \\
For & S.70, S.114 & Pasif \\
With & S.78, S.97 & Netral \\
Of & S.54, S.99 & Aktif \\
& S.89, S.90 & Pasif \\
\hline
\end{tabular}

\section{Pembahasan}

\section{Preposisi "against"}

Preposisi jenis ini banyak digunakan oleh Rouhani dalam pidatonya, tetapi bukan untuk menggambarkan posisi pelaku, malainkan untuk lebih menonjolkan adanya korban.

S.28. Propagandistic and unfounded faith phobic, Islam-phobic, Shia-phobic, and Iran-phobic discourses do indeed represent serious threats against world peace and human security.

(Wacana fobia agama, fobia Islam, fobia Syiah, dan fobia Iran yang propagandistik dan tidak berdasar jelas merupakan ancaman serius terhadap perdamaian dunia dan keamanan manusia).

Pada data S.28, HR menggunakan preposisi against untuk menunjukkan agresifitas para penyebar propagadanda dan wacana perang yang tidak berdasar dapat menjadi ancaman terhadap perdamaian dunia. Iran, yang dalam hal ini menjadi komoditi utama propaganda, juga tidak luput dari ancaman ini.

Hal yang sama juga terjadi ketika HR membahas krisis yang tengah melanda Timur Tengah.

S.37. Military intervention in Afghanistan, Saddam Hussein's imposed war against Iran,
occupation of Kuwait, military interventions against Iraq, brutal repression of the Palestinian
people, assassination of common people and political figures in Iran, and terrorist bombings in
countries such as Iraq, Afghanistan and Lebanon are examples of violence in this region in the last
three decades.
(Intervensi militer di Afghanistan, perang yang dipaksaan terhadap Saddam Hussein melawan Iran,
pendudukan Kuwait, intervensi militer terhadap Irak, represi brutal terhadap rakyat Palestina,
pembunuhan masyarakat umum dan tokoh politik di Iran, dan pemboman terhadap teroris di
negara-negara seperti Irak, Afghanistan dan Lebanon adalah contoh kekerasan di wilayah ini
dalam tiga dekade terakhir).

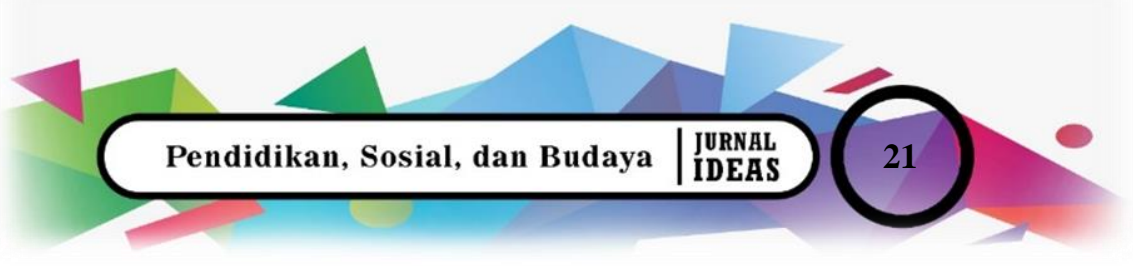


Preposisi against pada frasa Saddam Hussein's imposed war against Iran menjelaskan posisi Iran sebagai korban kekerasan oleh pihak tertentu yang memaksakan terjadinya perang Irak terhadap Iran. Begitu pula preposisi against pada frasa military interventions against Iraq. HR secara tidak langsung mengungkapkan bahwa langkah perang yang ditempuh oleh Irak bukan didorong oleh keinginan pemerintah Irak sendiri, melainkan karena adanya campur tangan militer negara lain. Hal ini tentu saja menunjukkan adanya upaya HR untuk menghilangkan kesan Irak sebagai pihak yang agresif dalam pusaran krisis di Timur Tengah.

Kendatipun demikian, HR tidak selalu menggunakan preposisi ini untuk menonjolkan korban dari sebuah peristiwa sosial.

S.104. Against the backdrop of this illegal and ineffective contention, let me say loud and clear that "peace is within reach.

(Bertentangan dengan perdebatan yang ilegal dan tidak efektif ini, saya katakan dengan tegas dan jelas bahwa "perdamaian berada dalam jangkauan).

Pada bagian ini, HR menggunakan preposisi against untuk menggambarkan dirinya selaku pemimpin Iran yang aktif menentang kekerasan dan aktif menempuh jalan perdamaian dalam mencari solusi terhadap krisis yang melanda Timur Tengah. Penggunaan yang berbeda atas preposisi against ini menggambarkan bahwa ketika membahas kekerasan dan ekstremisme di Timur Tengah, HR selalu menempatkan Iran sebagai korban. Sebaliknya, saat membahas usaha-usaha menentang kekerasan, HR menempatkan Iran sebagai pihak yang selalu berperan aktif. Pada titik ini, jelas bahwa HR memanfaatkan penggunaaan preposisi against untuk kepentingan dirinya dan Iran.

\section{Preposisi “among”}

Preposisi among tidak secara tegas merepresentasikan aktif atau pasifnya aktor sosial. Namun, konteks dapat menjelaskan hal ini.

S.21. In such an environment, governmental and non-governmental, religious, ethnic, and even racial violence has increased, and there is no guarantee that the era of quiet among big powers will remain immune from such violent discourses, practices and actions.

(Dalam lingkungan seperti itu, kekerasan governmental dan non-governmental, kekerasan agama, etnis, dan bahkan kekerasan rasial telah meningkat, dan tidak ada jaminan bahwa masa tenang di antara kekuatan-kekuatan besar akan tetap kebal dari wacana, praktik, dan aksi kekerasan seperti itu).

Data S.21 menunjukkan kekhawatiran HR akan adanya campur tangan kekuatan-kekuatan besar dunia terhadap setiap wacana maupun praktik kekerasan. Preposisi among di sini menggambarkan frasa nomina big powers sebagai aktor sosial yang berpotensi menjadi aktor sosial yang aktif dalam setiap aksi kekerasan di wilayah tersebut.

\section{Preposisi "between"}

Tak jauh berbeda dengan preposisi among, preposisi ini juga pada dasarnya merepresentasikan netralitas aktor sosial yang dimuatnya sebelum akhirnya konteks memberikan keberpihakan.

S.25. In this picture, the relation between the center of world power and the peripheries is hegemonic.

(Dalam konteks ini, hubungan antara pusat kekuasaan dunia dan negara-negara pinggiran adalah hegemoni).

Data S.25 pada dasarnya tidak secara jelas menunjukkan keaktifan dari aktor-aktor sosialnya baik the center of world power maupun the peripheries. Namun, adanya atribut is hegemonic tentu menyiratkan bahwa ada salah satu pihak yang memiliki hegemoni atas pihak yang lain. Sehingga, jika kita merujuk pada kalimat sebelumnya (S.24) maka dapat dipastikan bahwa pihak yang memiliki kuasa yang lebih besar adalah the center of the world power sedangkan pihak yang menenmpati strata kekuasaan yang lebih rendah adalah the peripheries.

Preposisi "by"

Preposisi jenis ini lebih banyak digunakan untuk menggambarkan pihak yang aktif terhadap isu-isu yang dimuat oleh proposisinya. 
S.7. Alongside these fears, however, there are new hopes; the hope of universal acceptance by the people and the elite all across the globe of "yes to peace and no to war"; and the hope of preference of dialogue over conflict and moderation over extremism.

(Di samping kekhawatiran ini, bagaimanapun, ada harapan baru, harapan penerimaan universal oleh rakyat dan elit di seluruh dunia dari "ya untuk perdamaian dan tidak untuk perang", dan harapan akan preferensi akan dialog terhadap konflik, dan moderasi terhadap ekstremisme).

Pada bagian ini, HR menggunakan preposisi by untuk mengilustrasikan bahwa harapan di balik semua ketakutan yang telah dijelaskan pada kalimat-kalimat sebelumnya, akan terwujud ketika semua orang, termasuk tokoh-tokoh elit di seluruh dunia, berperan aktif dalam upaya menentang kekerasan dan memilih jalan-jalan demokratis dalam penyelesaian konflik.

\title{
S.8. The recent elections in Iran represent a clear, living example of the wise choice of hope, rationality and moderation by the great people of Iran. \\ Pemilu yang baru-baru ini dihelat di Iran merepresentasikan contoh hidup yang jelas pilihan yang bijak dari Republik Rakyat Iran terhadap harapan, rasionalitas, dan moderasi.
}

Melalui data ini, HR menggambarkan rakyat Iran sebagai pihak yang aktif dalam mewujudkan demokrasi di Iran sebagai perwujudan dari harapan dan rasionalitas. Dalam hal ini, Iran lebih memilih wacana harapan daripada wacana ketakutan (S.7)

\begin{abstract}
S.45. While condemning any use of chemical weapons, we welcome Syria's acceptance of the Chemical Weapons Convention, and believe that the access by extremist terrorist groups to such weapons is the greatest danger to the region that must be considered in any disarmament plan. (Sembari mengutuk penggunaan senjata kimia dalam bentuk apapun, kami menyambut penerimaan Suriah terhadap Konvensi Senjata Kimia, dan percaya bahwa akses kelompokkelompok teroris ekstremis terhadap senjata seperti ini merupakan bahaya terbesar bagi wilayah ini yang harus dimasukkan dalam rencana pelucutan senjata mana pun).
\end{abstract}

Pada data tersebut, HR menunjukkan jaminannya kepada dunia bahwa program nuklir Iran tidak akan dapat diakses oleh ektremis maupun teroris manapun, sehingga, sebagaimana Suriah, negara-negara lain juga perlu mendukung program ini.

S.85. As clearly stated by the Leader of the Islamic Revolution, acceptance of the inalienable right of Iran constitutes the best and the easiest way of resolving this issue.

(Sebagaimana telah diutarakan dengan jelas oleh Pemimpin Revolusi Islam Iran, penerimaan terhadap hak absolut Iran merupakan cara terbaik dan termudah untuk menyelesaikan masalah ini).

Penggunaan preposisi by pada data S.85 mendeskripsikan kegigihan Pemimpin Revolusi Islam Iran yang meyakini bahwa tak ada solusi lain terhadap konflik program nuklir Iran kecali penerimaan dari semua negara.

Meski Iran tak gentar dengan penolakan negara-negara sekutu atas program nuklirnya, HR menegaskan bahwa Iran masih mempertimbangkan saran dari AS melalui Presiden Obama. Ini juga ditunjukkan pada data berikut.

\section{S.98. I listened carefully to the statement made by President Obama today at the General Assembly \\ (Aku mendengarkan secara seksama pernyataan Presiden Obama hari ini I depan Majelis Umum PBB).}

Penggunaan lain dari preposisi ini oleh HR adalah untuk mengindikasikan adanya marginalisasi oleh salah satu actor sosial terhadap aktor sosial yang lain, dimana Iran adalah salah satunya.

\section{S.24. The prevalent international political discourse depicts a civilized center surrounded by un- civilized peripheries. \\ (Wacana politik internasional yang lazim saat ini menggambarkan adanya pusat peradaban yang dikelilingi oleh pinggiran yang tidak beradab).}

Pada data S.24, tampak bahwa HR ingin menekankan bahwa salah satu penyebab konflik di Timur Tengah adalah marginalisasi terhadap negara-negara dunia ketiga yang dianggap tidak beradab jika dibandingkan dengan negara-negara besar. 


\section{Preposisi "from"}

Dalam pidatonya, HR hanya menggunakan preposisi sirkumstansial jenis ini satu kali, yakni sebagai berikut.

\section{S.101. Of course, we expect to hear a consistent voice from Washington.}

(Tentu saja, kami berharap untuk mendengar keputusan yang konsisten dari Washington).

Penggunaan preposisi from pada data S.101 menunjukkan ekspektasi HR terhadap peran aktif pemerintah AS yang konsisten dalam menahan diri untuk tidak menuruti propaganda dan wacana yang disebarkan oleh para penghasut (S.99).

\section{Preposisi “of"}

Preposisi ini banyak digunakan terutama untuk memisahkan secara jelas antara aktor sosial yang secara aktif menjadi pelaku dengan actor sosial yang secara pasif menjadi korban.

S.54. And contrary to the claims of those who pursue and impose them, it is not the states and the
political elite that are targeted, but rather, it is the common people who are victimized by these
sanctions.
(Dan bertentangan dengan klaim oleh pihak-pihak yang mengejar dan memaksakannya, bukan
negara dan elit politik yang menjadi target, melainkan rakyat yang menjadi korban sanksi-sanksi
tersebut).

Preposisi of pada data ini menempatkan rakyat jelata sebagai korban penerapan sanksi atas program nuklir Iran. Hal ini untuk menguatkan pernyataan HR sebelumnya (S.53) bahwa sanksi tersebut dipaksakan dan merupakan bentuk kekerasan strukturl yang tidak manusiawi.

S.99. Commensurate with the political will of the leadership in the United States and hoping that
they will refrain from following the short-sighted interest of warmongering pressure groups, we
can arrive at a framework to manage our differences.
(Sejalan dengan keinginan politik dari para pemimpin di Amerika Serikat dan dengan harapan
bahwa mereka akan menahan diri untuk tidak mengikuti kepentingan jangka pendek dari para
penekan dan penghasut, kita akan dapat menemukan kerangka kerja untuk mengatasi perbedaan
kita).

Penggunaan preposisi of pada data S.99 bertujuan untuk mengklasifikasi pihak-pihak yang secara vokal menolak program nuklir Iran sebagai penghasut sehingga harus diabaikan demi terwujudnya perdamaian antarnegara. Preposisi jenis ini juga digunakan oleh HR utuk menggarisbawahi kekuatan Iran di pentas dunia.

S.89-90. Iran's nuclear program - and for that matter, that of all other countries - must pursue
exclusively peaceful purposes. I declare here, openly and unambiguously, that, notwithstanding
the positions of others, this has been, and will always be, the objective of the Islamic Republic of
Iran.
(Program nuklir Iran, dan untuk hal ini semua negara lain, harus mengejar tujuan damai secara
eksklusif. Saya menyatakan di sini secara terbuka dan jelas bahwa terlepas dari posisi negara lain,
ini telah, dan akan selalu, menjadi tujuan Republik Islam Iran).

Preposisi of pada data S.89-90 mengilustrasikan usaha HR untuk menggambarkan Iran sebagai negara yang selalu berada pada garda terdepan dalam setiap usaha perdamaian dunia.

\section{Preposisi "under"}

Preposisi ini digunakan terutama untuk mengubah paradigma peristiwa ke paradigma aksi sosial yang menuntut adanya pelaku dan korban.

S.39. Palestine is under occupation; the basic rights of the Palestinians are tragically violated,
and they are deprived of the right of return and access to their homes, birthplace and homeland.
(Palestina berada di bawah pendudukan; hak-hak dasar rakyat Palestina dilanggar dengan tragis,
dan mereka kehilangan hak untuk kembali dan akses ke rumah, tempat kelahiran, dan tanah air
mereka).

HR memanfaatkan preposisi under pada data S.39 untuk mengubah paradigma tragedi kemanusiaan di Palestina menjadi aksi pendudukan. Hal ini tentu saja menjadikan actor sosial yang sebenarnya tidak ditampilkan menjadi inklusif. Sebagai sebuah aksi sosial, pendudukan tentu menuntut adanya pelaku, yang dalam hal ini adalah mereka yang melakukan pendudukan, dan menonjolkan korban, yang dalam hal ini adalah Palestina. 


\section{Preposisi "for"}

Preposisi for mendeskripsikan sosial actor yang menerima manfaat dari adanya aksi sosial yang direpresentasikan dalam wacana.

S.70. And this is a unique opportunity - for us all.

(Dan ini adalah kesempatan yang langka bagi kita semua).

S.114. Prudent moderation will ensure a bright future for the world.

(Moderasi yang bijaksana akan memastikan masa depan yang cerah bagi dunia).

Pada data S.70, frasa "kita semua" merupakan aktor sosial yang menerima manfaat dari lelahnya seluruh masyarakat dunia akan perang. Hasrat perubahan menuju perdamaian dianggap HR sebagai kesempatan yang langka. Frasa "dunia" pada data S.114 menjadi aktor sosial yang menerima manfaat dari langkah-langkah bijaksana yang ditempuh oleh semua negara dalam merespon segala konflik antarnegara.

Preposisi "with"

Preposisi with digunakan untuk menggambarkan peran netral aktor-aktor sosial dalam sebuah peristiwa sosial. Namun, keberadaan konteks dapat memisahkan peran aktif dan pasif dari actor-aktor sosialnya.

S.78. In foreign policy, the combination of these elements means that the Islamic Republic of Iran, as a regional power, will act responsibly with regard to regional and international security, and is willing and prepared to cooperate in these fields, bilaterally as well as multilaterally, with other responsible actors.

(Dalam politik luar negeri, kombinasi dari elemen-elemen ini berarti bahwa Republik Islam Iran, sebagai kekuatan regional, akan bertindak secara bertanggung jawab terkait keamanan regional dan internasional, serta bersedia dan siap bekerja sama di bidang ini, baik secara bilateral maupun multilateral, dengan actor-aktor lain yang bertanggung jawab).

S.97. Iran seeks constructive engagement with other countries based on mutual respect and common interest, and within the same framework does not seek to increase tensions with the United States.

(Iran berusaha terlibat secara konstruktif dengan negara lain berdasarkan rasa saling menghormati dan kepentingan bersama, dan dalam kerangka yang sama tidak berupaya meningkatkan ketegangan dengan Amerika Serikat).

Pada kedua data, meskipun semua aktor sosial yang terlibat dalam wacana tampak netral, HR secara implisit mengindikasikan bahwa dalam setiap upaya mewujudkan perdamaian dunia, Iran akan selalu menjadi inisiatornya.

\section{Simpulan}

Terdapat dua isu sentral yang menjadi pokok pembahasan HR dalam pidatonya, yakni kekerasan dan terorisme di Timur Tengah dan polemik program pengembangan nuklir Iran yang ditentang oleh banyak negara, khususnya Amerika Serikat dan sekutu utamanya, Israel. HR menggunakan preposisi sirkumstansial dengan pendekatan yang berbeda dalam mengulas tiap isu tersebut. Terkait kekerasan di Timur Tengah, HR memanfaatkan preposisi sirkumstansial beralokasi peran aktif against dan aktif-pasif of untuk menempatkan Iran sebagai korban serta preposisi sirkumstansial beralokasi peran aktif under dan aktif-pasif among untuk secara implisit menghadirkan aktor yang harus bertanggung jawab. Selain itu, HR juga menggunakan preposisi sirkumstansial beralokasi peran aktif by dan netral with untuk menunjukkan bahwa Iran akan selalu berada di garda terdepan dalam setiap usaha mewujudkan perdamaian di Timur Tengah. Selanjutnya, sebagai respon terhadap penolakan beberapa negara terhadap program pengembangan nuklir Iran, HR memanfaatkan preposisi sirkumstansial beralokasi peran aktif from untuk menyatakan harapannya agar Amerika Serikat sebagai kekuatan utama dunia tidak mengikuti seruan untuk menjatuhkan sanksi pada Iran. HR juga menegaskan pentingnya menyelesaikan segala bentuk masalah dan perselisihan tanpa melalui perang, termasuk dalam merespon polemik pengembangan nuklir Iran, sebagaimana tampak pada penggunaan preposisi sirkumstansial beralokasi peran pasif for.

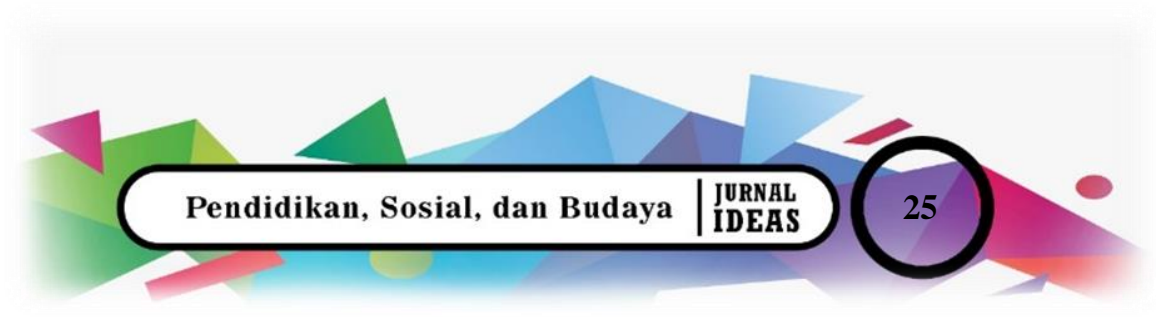


Volume : 7

\section{Daftar Rujukan}

Bernard, T. (2016). "They Came There As Workers": Voice, Dialogicality and Identity Construction in Textual Representations of the 2012 Marikana Miner'S Strike. Stellenbosch Papers in Linguistics Plus, 49(0), 145-165. https://doi.org/10.5842/49-0-662

de Oliveira, S. M. (2015). Discourses of inclusion and exclusion in the commemoration of the 40th anniversary of the Portuguese revolution. Journal of Social Science Education. https://doi.org/10.2390/jsse-v14-i2-1447

El Kadri, M. S. (2018). <b>The 'pibidian'identity: a critical discourse analysis of the 'pibidian' social actor in teacher education programs. Acta Scientiarum. Language and Culture. https://doi.org/10.4025/actascilangcult.v40i1.34887

Esmaeili, S., \& Arabmofrad, A. (2015). A critical discourse analysis of family and friends textbooks: Representation of genderism. International Journal of Applied Linguistics and English Literature, 4(4), 55-61. https://doi.org/10.7575/aiac.ijalel.v.4n.4p.55

Fairclough, I., \& Norman, F. (2013). Political Discourse Analysis: A Methods for Advanced Students. London: Routledge. Journal of Language and Politics, Vol. 12, pp. 295-304. https://doi.org/10.1075/jlp.12.2.07kie

Finlayson, A., \& Martin, J. (2008). "It Ain't What You Say..." British Political Studies and the Analysis of Speech and Rhetoric. British Politics, 3(4), 445-464.

Johnstone, B. (2008). Discourse Analysis, 2nd edn (2nd ed.). Oxford: Blackwell.

Roohani, A., \& Heidari, N. (2012). Evaluating an Instructional Textbook: A Critical Discourse Perspective. Issues in Language Teaching (ILT), 1(1), 123-158.

van Leeuwen, T. (2008). Discourse and Practice: New Tools for Critical Analysis. In Discourse and Practice: New Tools for Critical Analysis. https://doi.org/10.1093/acprof:oso/9780195323306.001.0001 